\title{
In Vitro Comparison of Two Ultrasonic Irrigation Needles for Dentin Debris Removal
}

\author{
Odeimi Gabrielle*, Nehme Walid and Naaman Alfred \\ Department of Endodontics, Saint-Joseph University, Lebanon
}

Submission:February 20, 2017 ; Published: April 13, 2018

*Corresponding author: c Odeimi Gabrielle, Department of Endodontics, Saint-Joseph University, Beirut, Lebanon, Email: gabrielle.odeimi@gmail.com

\section{Abstract}

Introduction: The aim of this study was to compare the removal of dentin debris from simulated canal irregularities in standardized root canals between two continuous ultrasonic-activated needles; the ProUltra ${ }^{\circledR}$ PiezoFlow (Dentsply Tulsa, OK) and the VPro ${ }^{\circledR}$ Stream clean System (Vista Dental Products, Racine, WI) when used as a final irrigation procedure.

Methods: 15 tooth models with four standard depressions in one canal wall and a standard groove in the other canal wall were reused in seven experimental groups. Ultrasonic activated irrigation was performed with the VPro and ProUltra inserted at 7, 5 and $3 \mathrm{~mm}$ short of Working Length (WL). Conventional irrigation was performed with the Vpro inserted at $1 \mathrm{~mm}$ short of WL without ultrasonic activation. The flow rate was $10 \mathrm{ml} / \mathrm{min}$ for all groups. The depressions and the groove were then photographed under stereomicroscope and the amount of dentin debris in each one was scored.

Results: A significant difference was found between the seven groups in the grooves (-p-value $<0.0001)$ and the depressions $(-p$-value $<0.0001)$. The overall cleaning efficacy decreased with increasing distance between the file and the apex. The amount of debris was significantly the lowest with ProUltra $3 \mathrm{~mm}$ short of WL and the highest in the group control.

Conclusion: Final irrigation with the ProUltra and VPro resulted in significantly less debris compared with conventional needle $(-$-value $<0.05)$. The ProUltra showed a better cleaning than the Vpro. Its effect was up to $2 \mathrm{~mm}$ beyond its tip contrary to the Vpro which cleaned only behind its tip.

Keywords : Passive Ultrasonic Irrigation; Conventional Irrigation; Insertion Depth; Dentinal Debris; Apical Cleaning

Abbreviations : WL: Working length, Ni-Ti: Nickel Titanium

\section{Introduction}

Syringe irrigation is the most popular irrigation technique. However, this technique produces irrigant exchange no farther than $1 \mathrm{~mm}$ beyond the needle tip and is ineffective in flushing debris from the apical third of the canal because of the typically challenging complexity of the root canal morphology [1-3]. Recent studies have shown that Passive ultrasonic irrigation can provide an advantage over conventional irrigation in apical debridement [4-8]. In fact, dentin debris, pulp tissue, and biofilm can be removed from the root canal wall by shear stress produced by acoustic streaming of the irrigant [9].

Two recently introduced systems; the ProUltra ${ }^{\circledR}$ PiezoFlow (Dentsply, Tulsa, OK) and the VPro® Stream Clean System (Vista Dental Products), ultrasonically activate a constant flow of irrigant. Rather than activating standing sodium hypochlorite in a canal, they consist of a needle that is activated ultrasonically while the $\mathrm{NaOCl}$ flows through it. The irrigation needles are attached to a piezoelectronic ultrasonic unit (Suprasson ${ }^{\circledR}$ P5 Booster). The VPro differs from the ProUltra by its irrigation needle that is made of Nickel Titanium (Ni-Ti) compared with Stainless steel, the needle gauge is narrower (\#30 vs \#25) and the irrigant flow rate is lower $(5-10 \mathrm{~mL} / \mathrm{min}$ vs $15 \mathrm{~mL} / \mathrm{min})$.

By lack of information concerning the apical debridement by the two systems, the aim of this study was to compare the mechanical cleaning efficacy of these needles with conventional syringe irrigation in the removal of dentin debris from simulated irregularities located at the apical area in standardized root canals.

\section{Materials and Methods}

\section{Dentin Debris Removal Model}

Straight roots from 15 extracted human mandibular canines were decoronated to obtain uniform root sections of $15 \mathrm{~mm}$ [9]. A mesio-distal radiograph was taken to ensure the presence of a single canal in all the teeth. The roots were embedded in resin and bisected longitudinally. The surfaces of both halves were then ground to leave only a little of the original root canal lumen. Four depressions were drilled in the resin part, and the two halves were reassembled by four self-tapping bolts through the depressions. 
Standardized root canals were established by K-flexofiles \#15/.02 (Dentsply Maillefer, Ballaigues, Switzerland) and GT (Dentsply, Maillefer) Ni-Ti rotary instruments to a WL of $15 \mathrm{~mm}$, an ISO size of 30, and a taper of 0.06. The final apical enlargement was performed with the Mtwo (VDW, Munich, Germany) Ni-Ti rotary instrument \#35/.04. During instrumentation, the canals were rinsed with $1 \mathrm{~mL}$ of $2 \% \mathrm{NaOCl}$ after each file delivered by a 10-mL syringe (Terumo, Leuven, Belgium) and a 30-G needle (Navitip; Ultradent, South Jordan, UT).
With the help of a stereomicroscope (magnification x10; Karl Kaps, SOM 22, Gmbh \& Co., Wetzlar, Germany) and a round bur (H71.104.003; Komet, Lemgo, Germany) attached to a drilling machine, four standard depressions $(\varnothing=0.3 \mathrm{~mm}$ ) located at 1 , 2,4 , and $6 \mathrm{~mm}$ from the WL were drilled in the wall of one half of each root canal (Figure 1A). A standard groove with $4 \mathrm{~mm}$ length, $0.5 \mathrm{~mm}$ deep, and $0.2 \mathrm{~mm}$ wide, situated at $2-6 \mathrm{~mm}$ from $\mathrm{WL}$, was also drilled in the wall of the other half of each root canal with a customized ultrasonic tip. The dimension of the groove is comparable to an apical oval root canal [10] (Figure 1B).

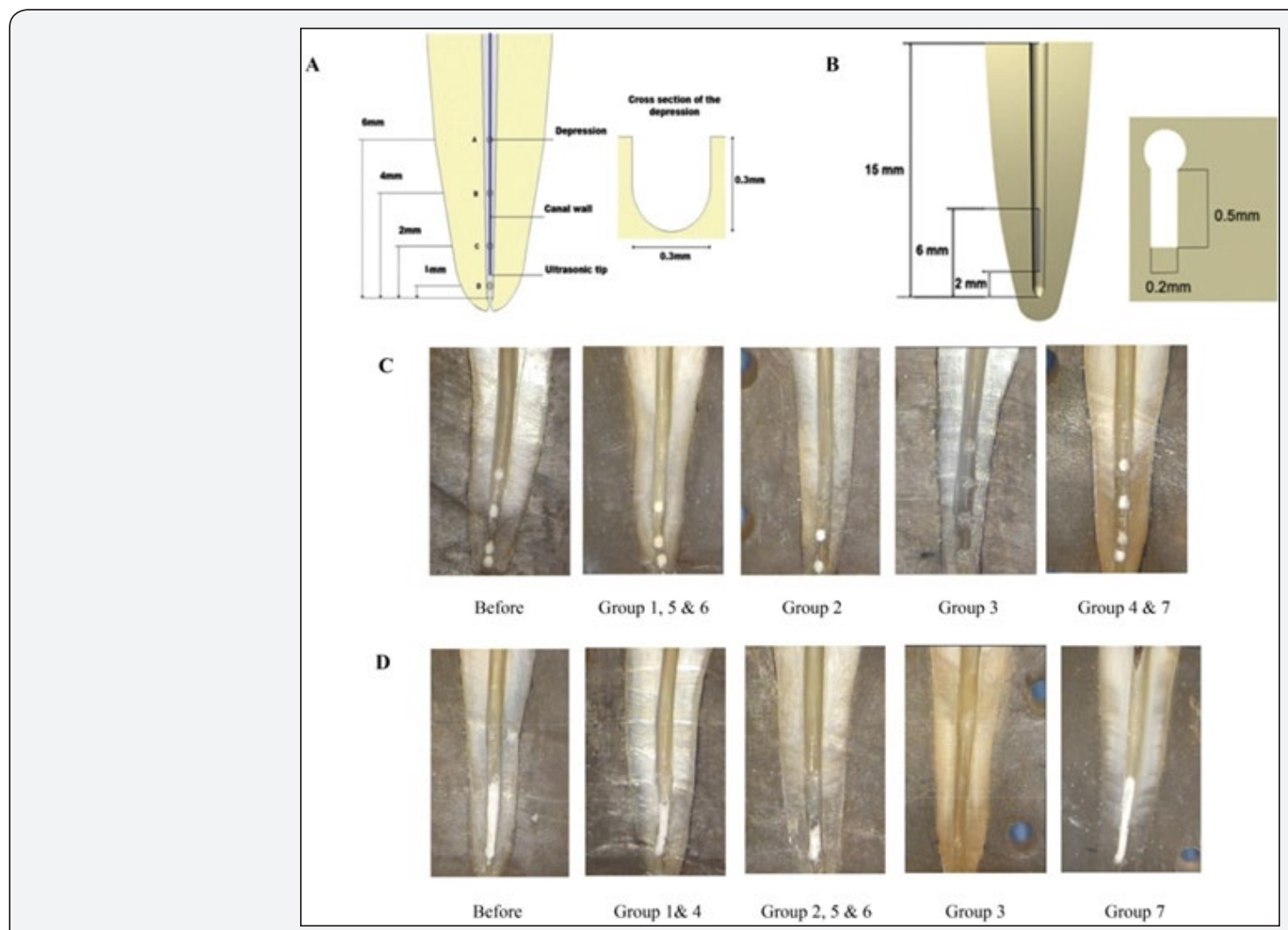

Figure 1: Schematic drawings of the depressions on one canal wall $(A)$ and the grooves on the other canal wall (B) and their typical images $(C$ and $D)$ before and after different irrigation procedures.

Each depression and groove was filled with dentin debris, which was mixed with $2 \% \mathrm{NaOCl}$ for 5 minutes in order to simulate a situation in which dentin debris accumulates in uninstrumented canal extensions [7,8]. These models were introduced to standardize the root canal space and the amount of dentin debris present in the root canal before the irrigation procedure to increase the reliability of the dentin debris removal evaluation. The methodology is sensitive, and the data are reproducible [11]. The 15 models were used repeatedly in the seven experimental groups [9].

\section{Irrigation Procedures and Experimental Groups}

Groups 1, 2 and 3 were irrigated using ProUltra. Groups 4, 5 and 6 were irrigated using Vpro. A $10 \mathrm{~mL}$ syringe containing $2 \%$ $\mathrm{NaOCl}$ was attached to the luer-lock connection on both needles. The inactive needles were placed into the canal, and the solution was delivered. Once irrigant filled the canal, the ultrasonic unit was activated with the power set to level 5. Maintaining a continuous irrigation flow, the ProUltra was gently inserted respectively to groups 1, 2 and 3 to 7, 5 and $3 \mathrm{~mm}$ short of WL and the Vpro was inserted respectively to groups 4, 5 and 6 to 7, 5 and $3 \mathrm{~mm}$ short of WL. Upon activation, the needles were moved up and down in a consistent straight-line path from the canal entrance to the length required. Group 7 was irrigated using Vpro placed $1 \mathrm{~mm}$ short of WL without being activated by ultrasound. The flow rate was $10 \mathrm{ml} / \mathrm{min}$ for 1 minute for all the groups.

\section{Image Evaluation and statistical analyses}

Before and after each irrigation procedure (Figure 1C \& 1D), the samples were evaluated by direct observation of images recorded under the dental operating stereomicroscope. 
Pictures were taken with a digital camera (Axio cam, Carl Zeiss). The orientation of all samples was standardized in relation to the recording microscope to produce similar images for all groups. The sequence of all the pictures was randomized.

The debris removal from each depression and groove after each irrigation procedure was scored independently and blindly by two trained, standardized and calibrated endodontists. The depressions were scoredas " 0 " if the depression was clean with only few particles and "1" if it was not completely clean. The outcome was assessed in each bloc at each of the 4 levels of depressions. The grooves were scored independently by using the following score system: " 0 " if the groove is empty; " 1 " if less than half is filled with debris; "2" if more than half is filled with debris and " 3 " if the complete groove is filled with debris. When the two evaluators differed in the scoring, an agreement was reached after discussion.

Statistical analyses were performed by a software program (SPSS for Windows, Version 18.0, Chicago, IL). The level of significance was set at $\alpha=0.05$. The Kendall's tau-b and Fisher Exact tests were conducted for comparison between distances and groups respectively.

\section{Results}

\section{Grooves}

The results are presented in Chart 1 . The amount of debris was significantly the lowest with ProUltra3mm and the highest in the control group (-p-value $<0.0001)$.

Chart 1: Percentages of grooves containing debris in each group

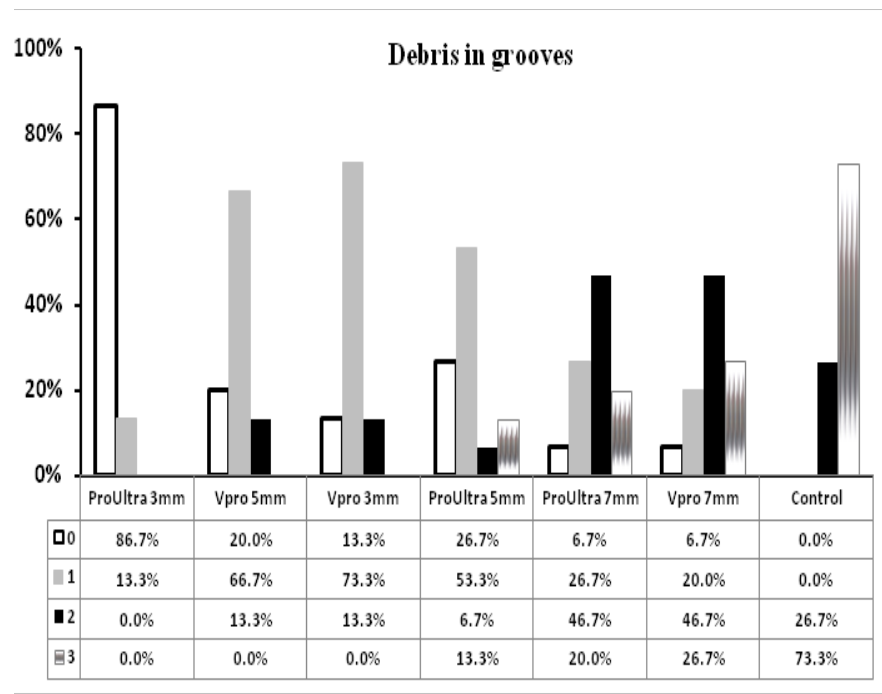

\section{Depressions}

Comparisons between depressions in each group: With ProUltra $7 \mathrm{~mm}$, the percentage of depression with debris was significantly lower at $6 \mathrm{~mm}$ from foramen $(26.7 \%)$ (-p-value $<0.0001)$. With ProUltra $5 \mathrm{~mm}$, it was significantly lower at $6 \mathrm{~mm}$ from foramen $(6.7 \%)$ followed by $4 \mathrm{~mm}$ depressions (33.3\%) (-p-value $<0.0001)$. With ProUltra $3 \mathrm{~mm}$, it was significantly lower at 6 and $4 \mathrm{~mm}$ from foramen (0\%), followed by the distance $2 \mathrm{~mm}(13.3 \%)$ and higher at $1 \mathrm{~mm}$ from foramen $(33.3 \%)$ $(-p$-value $=0.013)$. With Vpro $7 \mathrm{~mm}$, no significant difference was found between 1, 2, 4 and $6 \mathrm{~mm}$ (-p-value $=0.062)$. With Vpro $5 \mathrm{~mm}$, it was significantly lower at $6 \mathrm{~mm}(26.7 \%) \quad(-p$-value $<0.0001)$. With Vpro $3 \mathrm{~mm}$, it was significantly lower at $6 \mathrm{~mm}(13.3 \%)$ (-p-value $<0.0001)$. With control group, it was significantly lower at $6 \mathrm{~mm}(80 \%)(-p$-value $=0.027)$.

Comparison between the groups: The results are presented in Chart 2 Percentage of depressions without debris was significantly the highest with ProUltra $3 \mathrm{~mm}$ and the lowest in control group (-p-value $<0.0001)$.

Chart 2: Percentage of depressions containing debris in each group.

Presence of debris in depressions

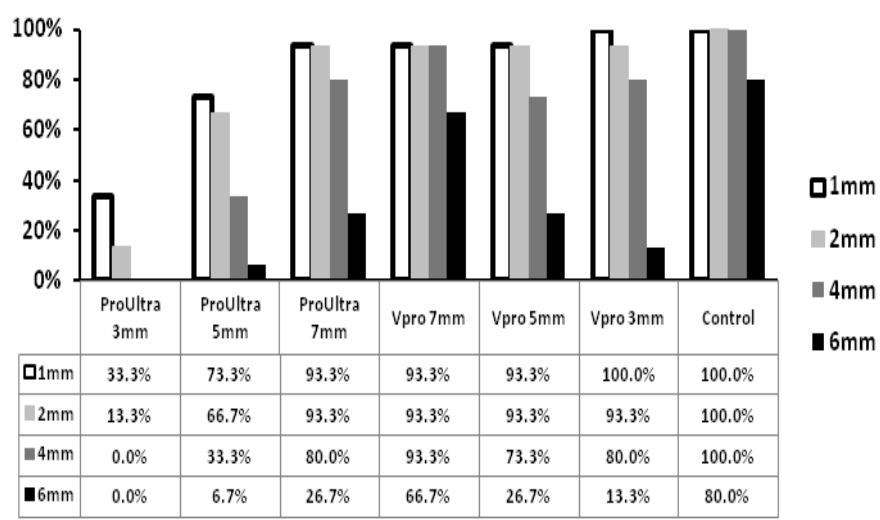

\section{Discussion}

The results of this study were in agreement with others [1215] which showed that the VPro and the ProUltra allowed better apical debridement compared with conventional syringe. It is generally admitted, that the mechanical cleaning is attributed to the flow velocity $[16,17]$. Indeed, when using the $30 \mathrm{G}$ needle, the flow velocity at the tip of the needle is expressed by the formula [18]:

$$
V_{1}=\frac{Q}{\pi r^{2}}
$$

Where $\mathrm{Q}$ is the flow rate, $\mathrm{R}$ is the radius of the needle.

When the needle is ultrasonically activated, a second velocity component $\left(\mathrm{V}_{2}\right)$ is added to $\left(\mathrm{V}_{1}\right)$ due to the vibration of the needle. It is expressed by the formula [18]:

$$
V_{2}=\frac{\omega \varepsilon_{0}^{2}}{\mathrm{R}}
$$

Where $\omega=2 \Pi f \quad$ (f is the oscillation frequency), $\varepsilon_{0}$ is the oscillation amplitude and $\mathrm{R}$ is the needle radius. $\mathrm{V}_{2}$ is responsible for acoustic turbulence and acoustic cavitation and has a value greater than $V_{1}$ [2]. These acoustic turbulences cause shear stresses on the canal walls that will remove debris dentin [15]. These shear stresses are directly proportional to the flow Velocity (V) according to the formula [17]: 


$$
\tau=\eta \frac{v}{\ddot{a}}
$$

Where $\eta$ is the kinematic viscosity of the liquid, $V$ the streaming velocity and the boundary layer thickness? And since the velocity flow with ultrasonic activation is greater than without activation, the shear stress will be higher [14]. In fact, Verhaagen et al. [18] showed that the shear stresses per unit area are about $1 \mathrm{~N} / \mathrm{m}^{2}$ for the conventional needle and $10 \mathrm{~N} / \mathrm{m}^{2}$ when the needle is ultrasonically activated resulting in a better mechanical cleaning of the root canal walls.

Concerning the grooves, there was a significant difference between the seven groups (-p-value $<0.0001)$. The ProUltra $3 \mathrm{~mm}$ short of WL was able in $86.7 \%$ of the cases to eliminate completely the debris compared to $13.3 \%$ for the Vpro $3 \mathrm{~mm}$ short of WL. But, the study of Jiang et al. [15] showed that $55 \%$ of the grooves were clean with the Vpro. This difference in results could be probably due to the insertion depth of the needle that is $1 \mathrm{~mm}$ short of $\mathrm{WL}$ in their study compared to $3 \mathrm{~mm}$ short of WL in ours. In the groove, the ProUltra showed a better cleaning efficiency. It was clear that the needles cleanse behind their tip but not clear how much do they cleanse ahead of them.

The position of the depression allowed us to calculate the efficiency of the needle to clean ahead of its tip. There was a significant difference between the seven groups (-p-value $<0.0001)$. The ProUltra $7 \mathrm{~mm}$ short of WL was able in most of the cases to clean $1 \mathrm{~mm}$ beyond its tip. The ProUltra $5 \mathrm{~mm}$ short of WL was able to clean $1 \mathrm{~mm}$ beyond and behind its tip. The ProUltra $3 \mathrm{~mm}$ short of WL was able in most of the cases to clean all the depressions, so the needle has cleaned $3 \mathrm{~mm}$ above and $2 \mathrm{~mm}$ beyond its tip. This is in agreement with the study of Castelo-Baz et al [12]. The reason why the ProUltra at $3 \mathrm{~mm}$ short of WL was better than the other levels of insertion could be explained by the formula:

$$
\mathrm{Q}=\mathrm{VxS}
$$

Where $\mathrm{Q}$ is the flow rate, $\mathrm{V}$ is the velocity flow and $\mathrm{S}$ is the canal section. For a constant flow rate, $\mathrm{V}$ and $\mathrm{S}$ are inversely proportional. The closer we get to $\mathrm{WL}$, the narrower is the canal, therefore $\mathrm{V}$ increases leading to a better apical debridement.

With the Vpro $7 \mathrm{~mm}$ short of WL, no depression was cleaned. The Vpro $5 \mathrm{~mm}$ short of WL was able to clean in most of the cases $1 \mathrm{~mm}$ behind its tip. The Vpro $3 \mathrm{~mm}$ short of WL was able in most of the cases to clean only the depression at $6 \mathrm{~mm}$ short of WL. This means that this instrument works probably behind its tip. Our results correlate with those of Curtis et al. [13].

This difference in results between the Vpro and ProUltra in depressions and grooves, where the ProUltra has a better apical debridement at different levels, can be explained by equation [16]. In fact, when the radius of the needle (R) increases, the flow velocity decreases. This means that the $30 \mathrm{G}$ needle should clean more than the $25 \mathrm{G}$ needle. But other than the radius of the file, the amplitude of oscillation also affects the velocity. Observations of
Verhaagen et al. [18] have shown that the amplitude of oscillation has increased with the increasing diameter of the needle. Thus, at a frequency $(\omega=2 \Pi f)$ set at $30 \mathrm{kHz}$ in dentistry and since the velocity is directly proportional to the square of the amplitude $\left(\varepsilon_{0}\right)$, and inversely proportional to the radius of the needle, the effect of the amplitude on the velocity will be much greater. For this $25 \mathrm{G}$ needle cleaned more that $30 \mathrm{G}$ needle.

Our study, using only straight canals has shown fracture of the Vpro (8/12). A previous study [19] also found that these needles fracture easily during ultrasonic activation. According to Al-Jadaa et al. [19], this is explained by the generated heat inside the metal upon activation, a fact that limits their usability in the clinic.

\section{Conclusion}

Through this work the ProUltra and Vpro allowed a better apical debridement compared with conventional irrigation. But the ProUltra $3 \mathrm{~mm}$ short of $\mathrm{WL}$, showed the most satisfactory results in the elimination of dentinal debris. The latter is able to clean $2 \mathrm{~mm}$ beyond and $3 \mathrm{~mm}$ behind its tip. On the contrary, the VPro was able to clean only behind its tip.

The cleaning efficacy of the $25 \mathrm{G}$ needle was observed in large straight canals where the needle reached freely the depth required. But further studies are needed to investigate the effectiveness of this needle in curved canals where the contact with canal walls is certain altering the acoustic micro streaming and cavitations.

\section{References}

1. Chow TW (1983) Mechanical effectiveness of root canal irrigation. J Ended 9(11): 475-479.

2. Ram Z (1977) Effectiveness of root canal irrigation. Oral Surg Oral Med Oral Pathol 44(2): 306-312.

3. Usman N, Baumgartner JC, Marshall JG (2004) Influence of instrument size on root canal debridement. J Endod 30(2): 110-112.

4. Adcock JM, Sidow SJ, Looney SW, Liu Y, McNally K, et al. (2011) Histologic evaluation of canal and isthmus debridement efficacies of two different irrigant delivery techniques in a closed system. J Endod 37(4): 544-548.

5. Burleson A, Nusstein J, Reader A, Beck M (2007) The in vivo evaluation of hand/rotary/ ultrasound instrumentation in necrotic, human mandibular molars. J Endod 33(7): 782-787.

6. Goodman A, Reader A, Beck M, Melfi R, Meyers W (1985) An in vitro comparison of the efficacy of the step-back technique versus a stepback/ultrasonic technique in human mandibular molars. J Endod 11(6): 249-256.

7. Lee SJ, Wu MK, Wesselink PR (2004a) The efficacy of ultrasonic irrigation to remove artificially placed dentine debris from different-sized simulated plastic root canals. Int Endod J 37(9): 607-612.

8. Lee SJ, Wu MK, Wesselink PR (2004b) The effectiveness of syringe irrigation and ultrasonics to remove debris from simulated irregularities within prepared root canal walls. Int Endod J 37(10): 672-678.

9. Jiang LM, Verhaagen B, Versluis M, Van der Sluis LWM (2010) Influence of the oscillation direction of an ultrasonic file on the cleaning efficacy of passive ultrasonic irrigation. J Endod 36(8): 1372-1376.

10. Wu MK, Wesselink PR (2001) A primary observation on the preparation and obturation of oval canals. Int Endod J 34(2): 137-141. 
11. Van der Sluis LWM, Versluis M, Wesselink PR (2007) Passive ultrasonic irrigation of the root canal: a review of literature. Int Endod J 40(6): 415-426.

12. Castelo-Baz P, Martin-Biedma B, Cantatore G, Ruiz-Piñon M, Rivas-Mundiña B, et al. (2012) In vitro comparison of passive and continuous ultrasonic irrigation in simulated lateral canals of extracted teeth. J Endod 38(5): 688-691.

13. Curtis TO, Sedgley CM (2012) Comparison of a continuous ultrasonic irrigation device and conventional needle irrigation in the removal of root canal debris. J Endod 38(9): 1261-1264.

14. Howard RK, Kirkpatrick TC, Rutledge RE, Yaccino JM (2011) Comparison of Debris Removal with Three Different Irrigation Techniques. J Endod 37(9): 1301-1305.

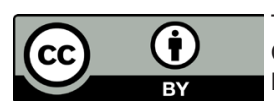

This work is licensed under Creative Commons Attribution 4.0 License

DOI: 10.19080/ADOH.2018.08.555739
15. Jiang LM, Lak B, Eijsvogels LM, Wesselink P, Van der Sluis LWM (2012) Comparison of the cleaning efficacy of different final irrigation techniques. J Endod 38(6): 838-841.

16. Ahmad M, Pitt Ford TR, Crum LA (1987) Ultrasonic debridement of root canals: acoustic streaming and its possible role. J Endod 13(10): 490-499.

17. Ahmad M, Pitt Ford TR, Crum LA, Walton AJ (1988) Ultrasonic debridement of root canals: acoustic cavitation and its relevance. J Endod 14(10): 486-493.

18. Verhaagen B (2012) Root canal cleaning through cavitation and microstreaming Enschede: Universiteit Twente, The Netherlands.

19. Al-Jadaa A, Paqué F, Attin T, Zehnder M (2009) Acoustic hypochlorite activation in simulated curved canals. J Endod 35(10): 1408-1411.

\section{Your next submission with Juniper Publishers will reach you the below assets}

- Quality Editorial service

- Swift Peer Review

- Reprints availability

- E-prints Service

- Manuscript Podcast for convenient understanding

- Global attainment for your research

- Manuscript accessibility in different formats

( Pdf, E-pub, Full Text, Audio)

- Unceasing customer service

Track the below URL for one-step submission https://juniperpublishers.com/online-submission.php 